\title{
Community-based tourism and the development of local small businesses in rural Baja California, Mexico
}

\author{
G. Velázquez ${ }^{1}$, J. Valderrama ${ }^{1}$, J. Ruiz ${ }^{1}$, O. Martínez ${ }^{1}$, L. Morales ${ }^{2}$, \\ R. Verján ${ }^{1} \&$ J. Flores ${ }^{1}$ \\ ${ }^{I}$ Tourism and Marketing School, Universidad Autónoma de Baja \\ California in Tijuana, México \\ ${ }^{2}$ Engineering and Business School, Universidad Autónoma de Baja \\ California in Ensenada, México
}

\begin{abstract}
Rethinking rural tourism as an alternative path toward sustainable tourism is the focus of this paper. Rural tourism involves leisure quality activities with greater advantages: it is done in the outskirts, causes low environmental and sociocultural impact, and provides experiences that enrich the spirit and personality of tourists. Furthermore, it helps understand the host rural communities through friendly and respectful contact, and at the same time it generates profitable revenue which accrues a beneficial effect on the aforementioned communities. An overall tourism-based strategy of local development will require, as a condition to its feasibility, to reassess the active role of the communities, recognizing that it is in their own geographical and social scenario where all touristic activities happens, even if those are classified as small-scale economic activities. Therefore, the strategic priority requires that the local host community should be involved in all the working processes from the beginning. Effective sustainable options should then start there, "from below", considering economic alternatives but above all being sensitive to natural, environmental and sociocultural viability, as well as taking into account the so-called "from the inside" perspective. Having started in 2003 and continuing to date, this academic task has provided to its contributors, Universidad Autónoma de Baja California researchers, the working experience with rural communities with feasible touristic possibilities. It has created, as well, the opportunity to get involved with
\end{abstract}


the small farming and fishing communities of Baja California. These communities are also beginning to think about social welfare opportunities linked to the development and strengthening of micro and small enterprises which offer touristic services on a small scale, operating on their own, and whose benefits represent a genuine option to reduce poverty, based not only on natural and cultural attractions but also through genuine local management, organization and work.

Keywords: rural tourism, sustainable development, communities, small businesses sustainable tourism, local population, tourism strategies, rural sites.

\section{Introduction}

It has become clear that rural communities, universities and local government in Baja California, México need an overall environmental and social framework within which the transformation of rural tourism can be accomplished and practiced. A shared framework is required in order to harness the available talent and thus, to solve the existing environmental and social problems of the area and be able to advance toward sustainable tourism. The United Nations World Tourism Organization (UNWTO) [1] asserts that sustainable tourism can be a tool for economic development and poverty reduction, arguing that tourism provides opportunities for selling additional goods, while creating opportunities for local economic diversification of poor and marginal areas without other development opportunities. Contradictory to the above circumstances in this case, success in rural tourism entrepreneurships is more feasible due to specific characteristics: the area counts with natural resources richness, possibilities and development opportunities. Moreover, these communities are next to the richest State (California) from one of the richest countries of the world: United States of America. In other words, there shouldn't be such a condition of poverty in these communities with so much wealth around.

\section{Tourism reasoning}

Rural tourism has been considered as an alternative activity, as a development intended for low environmental and socio-cultural impact that can be a positive and enriching experience for tourists, making accessible the understanding of the host communities reality through true coexistence based on direct communication with people. There are economic benefits for the host rural community associated to tourist services and an effective strategy for the preservation of natural and cultural resources.

In the context of tourism planning and development, community is ordinarily defined from a geographical perspective; as a body of people living in the same locality. However a second approach enables us to identify communities as a core of people organized and committed to their collective well-being, who live and maintain traditions strengthening their own life style, while surviving on traditional agriculture and livestock farming or fishing activities on small scales. Many of them react to the possibilities of the tourism market providing bed and 
breakfast accommodation, food and tour guide services on routes among other micro-enterprise activities associated to the tourism flow and the market opportunity brought in by it. The quality offer will be preceded by the organizational capacity available in their collective society.

The community enterprise model is slowly being adapted by the communities themselves to give more responsibilities to specialized, trained members of the community. Case studies indicate that joint ventures between a community or family and an outside business partner are frequently preferable because of the need for the community to connect its small-scale venture to the outside world (Epler Wood [4] and Stronza [5]).

In this social framework: "Receiving communities are a necessary component for the development of tourism". "Local participation can be defined as the ability of local communities to influence the outcome of tourist development projects that impact on them" (Masri de Achar et al. [2]) and must participate in all stages of the process, from the identification of needs and possibilities of attention, development, discussion, analysis of alternatives and decision-making on the allocation of resources, management and operation of programs, as well as the evaluation of the entire process of planning.

This local tourism development perspective should address not only under the partial consideration on opportunity to support intensive and immediate consumption of resources in the communities, whereas this is short-term situations associated with separate external proposals or initiatives of small groups locally. The proper implementation of strategies will require consensus and democratic participation of local integrated initiatives, reasoning and decision making, stimulating participation and the improvement of the local organization, encouraging the process of involvements with different levels of Governments, private and social organizations and associations.

It is recognized that "the biggest problem that exists to develop supply and marketing of rural tourism services lies in the large number of people that have to engage in the same" (Zamorano and Francisco [3]). In a sequential manner with service providers, owners, farmers, entrepreneurs, and municipal and local authorities with governmental institutions, among them NGOs; all this in order to ensure sustainability, social justice and equality (Figure 1).

The decisive participation of local people in the organization and management is required. Who better than them to know their problems, to determine how to meet local and their regional needs? "Who could be better than them to safeguard their inherited heritage and the culture of their community?" (Zamorano and Francisco [3]).

There is the deeply rooted belief which affirms that when communities are not able to clearly, conclusively and leadingly integrate the economic development perspective, by identifying the economic and social benefits in short and long term, as well as when omitting the evaluation of natural and cultural heritage impact throughout extensive time scenarios, there will exist, besides social segregation, an attractive and touristic resource status separation, proving a null plans and projects feasibility" (Valderrama et al. [6]). 


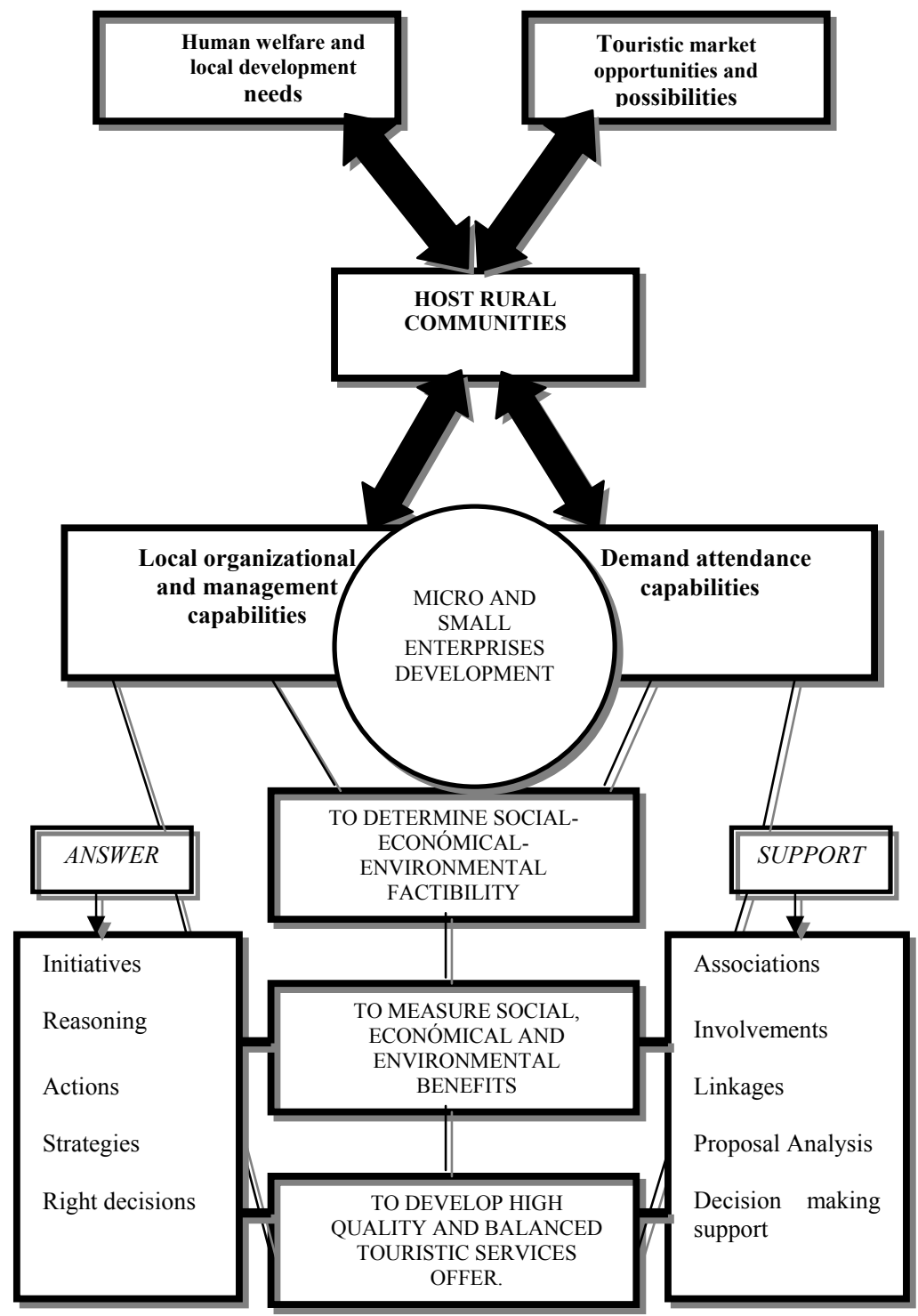

Figure 1: Entrepreneurship foundation and monitoring in touristic communities.

Going deeper into the scenery building task, it is acknowledged that as far as theoretical- referential sphere is concerned, "rural space is one of the places where facing modern frustrations and pressures finds its peaceful shelter, a place where sense of wonder can be recovered and regional sociocultural roots and manifestations can be approached" (Zamorano and Francisco [3]). Likewise, the possibility of articulating a series of strategies and objectives becomes viable, 
among these ones, stands out the fact of promoting compatibility between the touristic services development and natural preservation, as well as the creation of a decentralized small-scaled services offer which conforms local entrepreneurships and the development of communal management and operation abilities.

Furthermore accordingly, The World Tourism Organization has raised the need to continue studying travel expectations associated with a growing interest in learning about specific features of the chosen destination, noting that tourists are, shifting to an important market trend: the rapid growth of tourism of specific interests. A finding is that "There is a rise for the protection of the environment, combined with a higher level of education of tourists; the result will be more trips to less developed places." "In general, these tourists prefer local accommodations and points of interest and will want to know the local environment and culture." (World Organization of Tourism [7]).

\subsection{Local development}

Considering community-based strategy for local development must not only be an option in referential and theoretical discourse, but a real alternative for regions that have good social, environmental and economic conditions to work quality tourism projects.

Therefore, given the primary and strategic nature of the receiving communities, the jointed work approach is more than a condition, is a socially validated methodological requirement. Through a targeted effort, while considering theoretical principles tends to send a message of reachable goals: "sustainable tourist development is identified as a quality change process resulting from the political will the essential participation of the local people, it takes the institutional and legal framework as well as the planning and management tools, to a tourism development, based upon a balance between the conservation of the natural and cultural heritage, and the economic viability of tourism and the social development equity" (University of Alicante [8]).

Actually, quality tourism is the one developed in an integrated area where ecosystems, cultural expressions services and tourism entrepreneurships positive experiences among tourists and local residents, results in shared prosperity, higher levels of satisfaction of visitors and more revenue for those involved in tourism activities and in a significant way for host communities to take better advantage of tourism in their ongoing fight against poverty, generating conditions to develop permanent assessment, rational use and conservation awareness of existing resources. Thus, tourism development involves changes of attitude, responsibility and awareness, new lifestyles and human advancement.

The communities' capacity to response must be considered to achieve goals associated with the development project: "a series of strategies and actions by local groups must be taken to improve income, employment opportunities and their quality of life in response to market failures. Local development policies can also contribute to strengthen local participation and democracy" (Organization for Economic Cooperation and Development [9]). 
The Organization for Economic Cooperation and Development (OECD) warns that implementation approach will depend on specific local features, recognizing that most identified benefits include the promotion of selfemployment and the creation of new micro-enterprises, domestic investment attraction, networking, and support, coordination for social-economical promotion. According to the OECD among trends of local development policies recently experienced is the reorientation of economic and social policy towards development strategies "From the bottom-up" increasingly the validity and effectiveness of the endogenous development, promoting measures to the entrepreneurship and the development of capital support. Similarly increasing recognition skills, ideas and of the local population are indisputable strengths to support the creation and expansion of local businesses reviving traditional activities, strengthening the cultural heritage and responsibly in response to the expectations that tourism generates.

Local development must not continue being considered as an isolated process exclusively of endogenous nature, seeking to maximize the use of internal resources, but as a process established in a global context that strategically, responds to a valuable opportunity to touristic market, representing welfare, satisfaction and development for internal and external, perspective options to improve the quality of life, making the best use of social, economic and environmental accessible resources in the local area.

\subsubsection{University participation}

The process of defining the overall concept of "sustainable tourism development" is a social and academic task at hand that is not concluded and lacks the necessary deepness in theory to constantly evolve through practicalmethodological approaches to the actual living circumstances in Mexico, proposed and tested by universities, among those the Universidad de Autónoma de Baja California. These opportunities have made possible the beginning of strategic planning towards sustainable tourism development.

Under this design, sustainable tourism development should support primarily decisions to generate micro-enterprise developments, directed to strengthen work organization and the collective effort process and continuance of generating greater economic benefits that are able to improve the population's quality of life, promoting environmental policies and the preservation of the existing cultural resources. Without these essential conditions, plans and projects will not be successful.

For university students the start and development of the analysis and review of plans and strategies for sustainable tourism development, targets a more accurate description of the actual regional reality, provided the proper methodology is applied, and also providing valuable research and support documentation to attend the possibilities for connecting and an effective approach, positive academic participation of extended social participation.

Addressing two major concerns of Mexico's universities in their quest to support the economical forward advancement of this nation: (1) to promote and sustain the communities' welfare through income generated based in tourism 

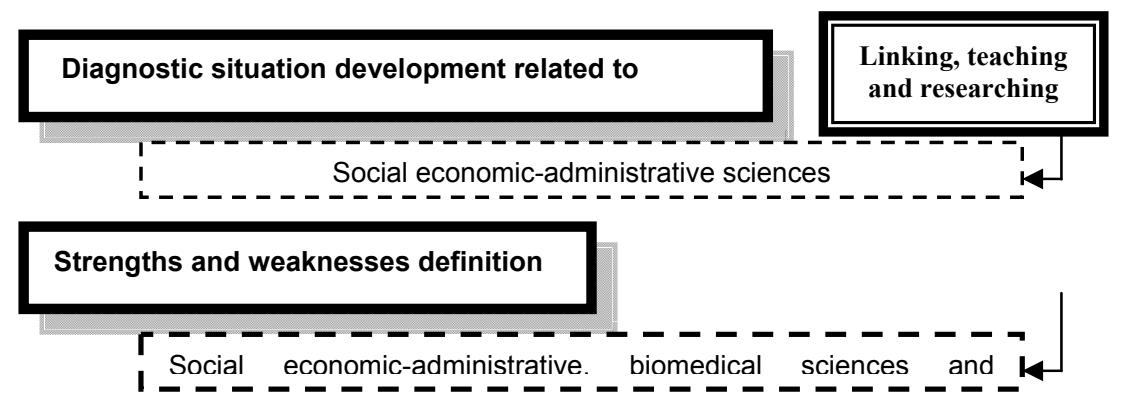

Real and potential heritage visualization

厂

Natural social technoloaical. economic-administrative sciences. $\mathbf{k}$

Authentic development objectives establishment

「 -

Social. natural. human. technoloaical. economic-administrative $\mathbf{K}$

Pro-community welfare and improvement actions

厂 - - - - - - - - - - - - - - - -

Social natural biomedical technoloaical economic-administrative $\mathbf{k}$

Development compatible strategies planning

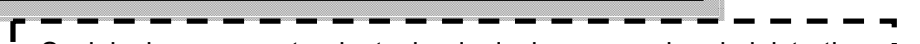
Social human natural technoloaical economic-administrative $\mathbf{k}$

Participation and management mechanisms implementation

「 - - - - - - - - - - - - - - - $\neg ~$ Social human natural technoloaical economic-administrative and $\mathbf{k}$

Microenterprises making up and strengthening

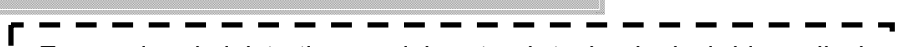

Economic-administrative social natural technoloaical biomedical $\mathbf{k}$

Evaluation and control mechanisms setting up

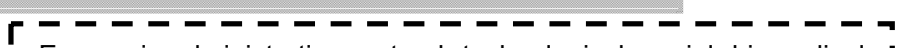

Economic-administrative natural technoloaical social biomedical $\mathbf{k}$

Figure 2: $\quad$ Strategic model for sustainable development linking university and touristic communities. 
activities; and (2) to strengthen higher education results. This relationship can be an excellent exchange for both university and community together, acting within the framework provided by the strategies process proposed (figure 2) combining development activities: different knowledge, skills and competences in each group of training expertise required for problem solving in each of the stages defined by the model itself, emphasizing the free participation of community and total respect for their characteristics and autonomy.

The strategic model focused on sustainable development strategies requires a serious commitment of students and faculty with communities and through significant learning achieving greater results from different scopes and combining knowledge from different careers. When achieved, they provide an indirect result: significant higher learning from direct actions. The experience of The Universidad Autónoma de Baja California is based on a flexible educational competencies model, consistent and appropriate to reduce the learning curve, combining theory and practice, knowledge and skill; allowing interdisciplinary and shared responsibility between student and teacher by learning immersed in reality and in problem solving actions.

The educational model consists of programmes focused on learning, how to develop skills to learn in life, to gather items in order to promote student autonomy development, critical thinking, collaborative and social attitudes, professional skills and self-assessment capacity; its strength enables students to be the core of the educational process requiring new ways of conceiving substantive functions of teaching, research and extent.

Such facts, regarding the undergraduate tourism degree current plan and following the guidance of teachers and tutors, enable students to participate actively deciding their training, context, promoting extra class activities, including fieldtrips practices, researching workshops exercises, independent studies, as well as social and professional services among other options. Those elements will build the framework within which they will become into learning and reinforcing knowledge and learning skills by summing up all these efforts in order to strengthen their training capacity and enhancing their effective incorporation into professional paths.

When applying this strategic model into sustainable development issues, university participation's character and attainment is defined. Furthermore, it copes with the challenge of becoming it reachable to the community in such way that this implementation should just mean a guideline and a support opportunity when making decisions. Consequently, during this process, a coordinated responsibility will be created by bringing out a valuable two-way learning, based on one of the sustainable formation postulates: "to teach in order to learn and to learn by teaching". Therefore, if the community preserves its own dynamics' prominence while universities (with public founding resources) access to society through its meaningful learning; the aforementioned postulate will become into an attainable goal. Moreover, this scope should integrate- to its current needmeeting and consistent programs and structures - a social changing catalytic sponsor such as this university mission could be. 
The previous statements define which part should social actors play accordingly to their own active, responsible and proficient role, asserting that planning and management require an external linkage and local strengthening relation - respectfully coordinated in order to avoid any kind of dependencebut instead, in order to truly reinforce the right communities have to decide their development and which will meet academics' social involvement needs and their valuable participation.

\section{Conclusions}

The possibilities of responsible and committed host rural communities' participation - which rightfully meet local welfare needs during the planning implementation and development processes - are being weighted up, here and now. These opportunities should be promoted, as well, taking into account local entrepreneurships and small enterprises creation which respond to tourist market expectations, as part of a series of strategies and community actions to strengthen partnerships and involvement with different agents and institutions which will eventually produce better and greater scopes, by determining plans and projects socio-economic and environmental feasibility.

Nowadays, local development strategies are set out as viable alternatives for social, environmental and economic profitable sites and regions which are suitable to practice high-quality tourism. Such sort of tourism should establish; on a short, medium and long term basis, an equilibrated outline merging social equity, economic feasibility, as well as, natural and cultural heritage preservation.

In present times, high-quality tourism could be defined as the one which is performed within a well-bounded space where cultural manifestations, nature and authentic products-services should favour a better reality understanding of hostess communities and a highly valued coexistence between local inhabitants and tourists. Therefore, in order to set up and develop such strategies it is of paramount importance that local settlements participate being leaded by reasoning and decision, and thus, improving their domestic organisation and enhancing the establishment of individual, different governmental levels, universities and social organizations relationships, among other entities.

Under this perspective, Baja California State, located within Mexico's territory, along with Ensenada's regional wine industry and touristic area, as well as Guadalupe Valley communities must be considered as an exemplary, unbeatable and high-quality touristic product which stands out due to its peerless advantages.

Such consideration should be possible if deeper planning and labour are undertaken around a general sustainable touristic development which will permanently reassess existing environmental, social, cultural, historical, and economic conditions.

Rural tourism in Baja California can be an activity daring to generate economic direct benefits for integrated services providers, especially for low income families. These quality consumer activities will become into tangible 
opportunities provided that such purveyors launch complementary and strengthening new entrepreneurships enhancing the current touristic offer. Eventually, those innovative projects should be based on their own outstanding qualities and community organization skills, as well as being supported by associations and favored bonds; turning out into increasing levels of customer satisfaction and promoting overall tourism participants' well-being.

\section{Acknowledgements}

Technical and language support: (Spanish to English version, resources, proofreading, linguistic and style correction and/or improvement) by Carmen Alejandra González-Velázquez Languages Bachelor's degree graduate, (Interpretation and Translation specialization areas) and CPA Alejandro Montijo-Velázquez, June 2010.

\section{References}

[1] Organización Mundial del Turismo. Turismo Sostenible: Factor fundamental para la erradicación de la pobreza en Colombia. Informe del IV Seminario Internacional. Bogotá, Colombia 22-23 de Junio de 2006.

[2] Masri de Achar Sofía, Robles Ponce, Luisa M. La industria turística: Hacia la sustentabilidad. Editorial Diana. México.1997.

[3] Zamorano Casal, Francisco Manuel. Turismo Alternativo: Servicios Turísticos Diferenciados. Editorial Trillas, México. 2002.

[4] Epler-Wood, M., Meeting the Global Challenge of Community Participation in Ecotourism: Case Studies and Lessons from Ecuador. America Verde Working Papers No. 2. The Nature Conservancy. The Ecotourism Society (1998) Retrieved: June-18-2010 from: http://www.nature.org/aboutus/

travel/ecotourism/files/america_verde_commnity_participation_english.

[5] Stronza, A. because it is ours: Community-based ecotourism in the Peruvian Amazon, a dissertation presented to University of Florida, Gainesville, FL, USA 2000.

[6] Valderrama Martínez, Jorge Antonio - Velázquez Romero María Guadalupe. - Flores Trejo, Juan Carlos. La importancia de las comunidades receptoras dentro de la perspectiva del desarrollo turístico sustentable. En Revista Intercontinental Ducit et Docet de Investigación. Vol. 5 Numero 2 Julio-Diciembre de 2004. Universidad Intercontinental. México.

[7] Organización Mundial del Turismo. Desarrollo turístico Sostenible. Guía para planificadores locales. España, 1993.

[8] Universidad de Alicante. Instituto Planificación y gestión del desarrollo turístico sostenible: Propuesta para la creación de un sistema de indicadores. Instituto Universitario de Geografía. Documentos de trabajo No. 1 España, 2001. 
[9] Organización para la Cooperación y el Desarrollo Económico. Mejores prácticas de desarrollo local. Economía Territorial. Librería El Correo de la UNESCO, S.A. Cuaderno de Trabajo 27. México 2002

[10] Rozo. Edna: El turismo sustentable como promotor de desarrollo de las comunidades locales en: Turismo y Desarrollo Sostenible. Compilador Meyer Krumhalz, Daniel. Universidad de Externado de Colombia, 2002. 